\title{
Maternal use of montelukast in early pregnancy and infant congenital malformations
}

\author{
Bengt Källén* \\ Tornblad Institute, University of Lund, Lund, Sweden
}

\begin{abstract}
Background: Only few studies are published about maternal use of montelukast in early pregnancy and infant congenital malformations.

Material: The study was performed on data from the Swedish Medical Birth Register. Between 1999 and 2013 , 633 women prospectively reported the use of montelukast in early pregnancy. The rate of congenital malformations and certain types of malformations were compared with corresponding rates in the general population after adjustment for year of birth, maternal age, parity, smoking in early pregnancy and pre-pregnancy body mass index. Another comparison group consisted of infants whose mothers had used long-acting adrenergic drugs or inhaled corticosteroids but not montelukast.
\end{abstract}

Results: A total of 30 malformed infants were identified, OR=1.07 (95\% confidence interval 0.74-1.55) after montelukast exposure. Among them 23 were relatively severe, $\mathrm{OR}=1.17,95 \% \mathrm{CI} 0.77-1.78$. Eight had cardiovascular defects (RR=1.16, 95\% CI 0.50-2.29). Similar risk estimates were seen in the comparison group, then statistically significant.

Conclusion: More information is needed about use of montelukast in early pregnancy but at present no major teratogenic effect is found and the weak effects seen are similar to those seen after other anti-asthmatic drugs and may be a result of the underlying asthma disease.

\section{Introduction}

Montelukast is a leukotriene receptor inhibitor, in Sweden mainly used as an asthma medication or at allergic rhinitis. Its use during pregnancy has been studied in a limited number of investigations. In a pregnancy register of montelukast, kept by Merck, a clustering of six transverse limb reductions was noted [1]. The first epidemiological study identified 190 infants, exposed in early pregnancy to montelukast, seven of them with malformations among which three had cardiac defects [2]. A small study was published on leukotriene receptor antagonists (72 montelukast, 22 zaforlukast and 2 with both drugs) among which $85 \%$ had used the drug during the first trimester. One concluded that the malformation risk was increased compared with unexposed infants but similar to that in infants treated with other asthma drugs [3]. Another small study identified 160 livebirths exposed to montelukast ( $90 \%$ of them during the first trimester) with only one twin infant with a cardiac defect -one fetus with Down syndrome had been aborted after prenatal diagnosis [4].

The largest study comes from Merck as a letter to the Editor [5]. This study identified maternal exposure to montelukast during the first trimester from a prescription register and presence of congenital malformations in the infants from insurance claims. A total of 1,187 first trimester exposures were identified and compared with 5,018 exposures for inhaled corticosteroids and 38,828 unexposed controls. A number of different malformations were identified and the percentage of certain heart malformations (14 cases) was higher after montlukast than in the two comparison cohorts ( $1.2 \% v s .0 .7 \%)$. This was also the case for malformations in the digestive tract (based on 6 cases) and "other congenital limb anomalies" (ICD-9 code 755, 16 cases). A detailed analysis of the latter revealed no case of a limb reduction of the type observed in the pregnancy register (but one case had an unspecified lower limb malformation) and most of the limb anomalies were poly- or syndactyly or hip subluxation. No adjustment for putative confounders was presented.

The present report is an update from the Swedish Medical Birth Register. The total number of exposed infants is a little more than half of the number in the study mentioned [5] above but larger than in other previous studies.

\section{Material and methods}

Data were obtained from the Swedish Medical Birth Register, where information on maternal drug use is obtained from midwife interviews in early pregnancy (usually in week 10-12) [6]. The register also contains information on maternal characteristics which may confound the analysis [7]. Congenital malformations in the infants were identified from three sources: diagnoses given in the Medical Birth Register at the pediatric examination of the newborn, diagnoses from the Birth Defect Register (previous Register of Congenital Malformations) and from discharge diagnoses in the Hospital Discharge Register [8]. Linkage between registers was made with the unique personal identification number each person living in Sweden has.

Statistical analysis was made with the Mantel-Haenszel method, comparing malformation rate among exposed infants with the malformation rate among all other infants, adjusted for year of

Correspondence to: Professor Bengt Källén, Tornblad Institute, Lund University, SE-22100, Lund, Sweden, Tel: +46-46-2227536; E-mail: Bengt.Kallen@med.lu.se

Received: February 02, 2016; Accepted: February 29, 2016; Published: March 02,2016 
birth, maternal age, parity, maternal smoking in early pregnancy, and pre-pregnancy body mass index (BMI). Risks were expressed as odd ratios (OR) with $95 \%$ confidence intervals $(95 \% \mathrm{CI})$. When the observed number of exposed cases was $<10$, risk ratios (RR) were instead calculated as observed/expected numbers (expected numbers calculated with adjustments as above) and the 95\% CI was based on exact Poisson distributions. The first woman who reported the use of montelukast in early pregnancy was delivered in 1999. As data were only available up to and including 2013, the analysis was made for the period 1999-2013.

The definition of a group of "other congenital limb anomalies" followed that used by Nelsen et al. [5].

For comparison a material was prepared of infants whose mothers had reported the use of long-acting adrenergic drugs and/or inhaled corticosteroids but not montelukast.

\section{Results}

During 1999-2013, 1,528,044 infants were registered in the Medical Birth Register. Among them, 633 were born in 624 deliveries of women who had reported the use of montelukast in early pregnancy. In the comparison group there were 24,547 infants exposed to other longacting adrenergic drugs and/or inhaled corticosteroids.

Table 1 shows some maternal characteristics. Use of montelukast increased with a maternal age over 35 , decreased with parity and increased at obesity. There was no certain effect of maternal smoking. There were nine twin deliveries.

The characteristics of women who had reported the use of long.acting adrenergic drugs or corticosteroids were similar but the effect of parity was less marked than for montelukast and the effect of smoking was clear-cut.

In 99 women, montelukast was the only anti-asthmatic drug reported. Eighty-two women reported one, 268 two, 161 three, 13 four and one five further anti-asthmatics. Table 2 shows the nature of the simultaneously used anti-asthmatics.

Among the 663 montelukast-exposed infants, 30 had a congenital malformation. Table 3 lists the identified malformations and Table 4 gives ORs for some groups. None reaches statistical significance but the OR for the heterogeneous group "other congenital limb defects" is relatively high. This group contains poly- or syndactyly, unstable hip, arthrogryposis and one unspecified limb malformation. In the group of infants whose mothers had used other long-acting anti-asthmatics than montelukast, there was a significant increase of any malformation, of relatively severe malformations and of cardiovascular defects. The estimates for the two groups were rather similar except for the "other congenital limb defects", but the higher RR for the montelukast group was not statistically significant.

\section{Discussion}

The present study has the advantage that it is based on exposure information obtained in early pregnancy without recall bias and on independent outcome registers. The disadvantage is that information of the time of usage is crude: only that it was used during pregnancy before the first prenatal visit which usually takes place in weeks 10-12. Furthermore there is no information on dosage, but the standard dose of montelukast in adults is $10 \mathrm{mg} /$ day.

The number of montelukast-exposed infants is not very large but there is only one previous large material published [5], nearly twice the

Table 1. Some characteristics of women reporting the use of montelukast or other anti-asthmatics* in early pregnancy. Odds ratios (OR) with $95 \%$ confidence intervals (95\% CI). For each variable, adjustment was made for the other variables. Bold text marks statistical significance.

\begin{tabular}{|c|c|c|c|c|c|c|c|}
\hline Variable & Population & $\begin{array}{c}\text { With } \\
\text { monte-lukast }\end{array}$ & OR & $95 \%$ CI & $\begin{array}{c}\text { With other } \\
\text { anti-asthmatics* }\end{array}$ & OR & $95 \% \mathrm{CI}$ \\
\hline \multicolumn{8}{|l|}{ Maternal age } \\
\hline$<20$ & 25568 & 12 & 0.97 & $0.53-1.77$ & 446 & 1.02 & $0.93-1.13$ \\
\hline $20-24$ & 195988 & 86 & 0.92 & $0.71-1.19$ & 3225 & 0.96 & $0.92-1.01$ \\
\hline $25-29$ & 455097 & 193 & 1.00 & Reference & 7133 & 1.00 & Reference \\
\hline $30-34$ & 521625 & 174 & 0.89 & $0.72-1.09$ & 8139 & 1.02 & $0.99-1.06$ \\
\hline $35-39$ & 255672 & 130 & 1.34 & $1.05-1.71$ & 4314 & 1.14 & 1.09-1.18 \\
\hline$\geq 40$ & 51823 & 29 & 1.62 & $1.06-2.50$ & 933 & 1.22 & $1.13-1.32$ \\
\hline \multicolumn{8}{|l|}{ Parity } \\
\hline 1 & 674350 & 371 & 1.00 & Reference & 11782 & 1.00 & Reference \\
\hline 2 & 545126 & 167 & 0.52 & $0.44-0.63$ & 7910 & 0.78 & $0.76-0.80$ \\
\hline 3 & 199886 & 63 & 0.49 & $0.36-0.65$ & 3102 & 0.80 & $0.76-0.83$ \\
\hline$\geq 4$ & 86415 & 23 & 0.35 & $0.22-0.56$ & 1396 & 0.73 & $0.89-0.78$ \\
\hline \multicolumn{8}{|l|}{ Smoking } \\
\hline Unknown & 87228 & 4 & - & - & 393 & - & - \\
\hline None & 1301806 & 574 & 1.00 & Reference & 21387 & 1.00 & Reference \\
\hline$<10$ cigs/day & 86370 & 32 & 0.82 & $0.57-1.18$ & 1706 & 1.07 & $1.02-1.13$ \\
\hline$\geq 10$ cigs $/$ day & 30373 & 14 & 1.36 & $0.80-2.32$ & 704 & 1.36 & $1.26-1.47$ \\
\hline \multicolumn{8}{|l|}{ BMI } \\
\hline Unknown & 162259 & 32 & - & - & 1620 & - & - \\
\hline$<18.5$ & 32625 & 12 & 0.90 & $0.51-1.59$ & 479 & 0.98 & 0.89-1.07 \\
\hline $18.5-24.9$ & 817784 & 320 & 1.00 & Reference & 11728 & 1.00 & Reference \\
\hline $25-29.9$ & 336874 & 163 & 0.73 & $0.60-0.88$ & 6303 & 0.77 & $0.75-0.80$ \\
\hline $30-34.9$ & 110549 & 65 & 1.30 & $0.99-1.71$ & 2652 & 1.45 & 1.39-1.51 \\
\hline$\geq 35$ & 45686 & 41 & 2.15 & $1.55-3.00$ & 1408 & 2.05 & 1.94-2.17 \\
\hline
\end{tabular}


size of the present material. In that report, no adjusted risk estimates were presented but the numbers of malformation cases in different groups of malformations were given. Among 20 such groups, four showed marked rate differences when compared with the reference cohort of non-asthmatic cases or the cohort treated with inhaled corticosteroids. These are shown in Table 5 with crude odds or risk ratio estimates, calculated from the numbers given in that paper. There were three groups of cardiovascular defects. One group (bulbous or septal defects) showed similar rates in the three groups, one (other cardiac defects) showed a statistically non-significant increase when

Table 2. Simultaneous use of other anti-asthmatic drugs together with montelukast.

\begin{tabular}{|l|c|}
\hline Type of anti-asthmatic & Number of women \\
\hline Short-acting adrenergic drugs & 291 \\
\hline Long-acting adrenergic drugs & 375 \\
\hline Inhaled corticosteroids & 456 \\
\hline Anticholinergic drugs & 13 \\
\hline Cromoglicic acid & 11 \\
\hline Xanthines & 16 \\
\hline Systemic corticosteroids & 0 \\
\hline
\end{tabular}

Table 3. List of congenital malformations after exposure to montelukast in early pregnancy.

\begin{tabular}{|l|c|}
\hline Malformation & Number \\
\hline Relatively major malformations & \\
\hline Encephalocele & 1 \\
\hline Unspecified CNS malformation + VSD +ASD + pulmonary valve stenosis & 1 \\
\hline Truncus arteriosus & 1 \\
\hline VSD & 4 \\
\hline Pulmonary valve stenosis & 1 \\
\hline Tricuspidal stenosis & 1 \\
\hline Unspecified cardiac defect & 1 \\
\hline Laryngeal stridor, tracheomalacia & 2 \\
\hline Pylorostenosis & 1 \\
\hline Medullary cystic kidney with hydronephrosis & 1 \\
\hline Hydronephrosis & 1 \\
\hline Pes equinovarus & 2 \\
\hline Polydactyly & 2 \\
\hline Syndactyly & 1 \\
\hline Unspecified malformation upper limb (no reduction) & 1 \\
\hline Arthrogryposis & 1 \\
\hline Deletion chromosome 4 & 1 \\
\hline Less severe and variably recorded malformations & 2 \\
\hline Tongue tie & 1 \\
\hline Undescended testicle1 & 2 \\
\hline Hip subluxation/unstable hip & \\
\hline $\begin{array}{l}\text { ASD = atrium septum defect, CNS = central nervous system, VSD = ventricular septum } \\
\text { defect }\end{array}$ & \\
\hline Table & \\
\hline
\end{tabular}

compared with the population but not when compared with infants exposed to inhaled corticoids (ICS), and the third group (non-cardiac circulatory defects) showed a significant increase compared with the reference group and a higher but not statistically significant increase compared with the ICS group. It can be noted that this malformation group includes patent ductus arteriosus - an increased risk for this condition could be the result of the well-known increased risk of preterm births at maternal asthma. Also in the present study there was an increased risk for cardiovascular defects (excluding preterm patent ductus arteriosus), similar in size in the montelukast and the asthma comparison group but not statistically significant in the former.

The increase in "lower digestive malformations" was based on few cases and not statistically significant - in the present material there was no such case after montelukast exposure. In the asthma comparison group there were 80 infants with anal atresia, OR=1.12 (95\% CI 0.901.40). The population rate was 3 per 1000 infants.

The last group showing an excess in the Nelsen et al. [5] paper consisted of limb defects of a non-deformity type (thus for instance pes equino-varus was not included but arthrogryposis and hip dislocation was). The increase compared with the reference cohort was statistically significant while the excess compared with the ICS cohort could be random. Also in the present material such an increase was indicated after montelukast even though statistical significance was not reached. No such increase was seen for the asthma comparison cohort. In the two large montelukast studies when added, 25 infants were recorded with such malformations. Among them 13 had unstable hip and nine had polydactyly or syndactyly. Among the remaining three infants, there was one with arthrogryposis and two with unspecified lower limb malformations. In none of the two small studies [3,4] were malformations of this type reported.

Hip dysplasia is a relatively mild anomaly, the rate of which varies considerably between hospitals and with year of birth depending on the diagnostic criteria applied and also varies with gestational duration [9]. There is also a variation of the rate of polydactyly (notably of postaxial polydactyly) and of syndactyly (notably of webbing of toes). Crude comparisons of the rates of these relatively common anomalies are therefore not very useful.

\section{Conclusion}

There are now two relatively large studies on the use of montelukast in early pregnancy. It seems likely that the indicated weak teratogenic effect of this drug is similar to that of other drugs used for long-term treatment of asthma, probably explained by an effect of underlying disease.

Ethics: The data for this study were collected as part of the routine analysis of drug use during pregnancy by the National Board of Health

Table 4. Odds ratio (OR) or Risk Ratio (RR) for congenital malformations after maternal use of montelukast or other long-acting anti-asthmatic drugs, adjusted for year of birth, maternal age, parity, smoking and BMI. Bold text marks statistical significance

\begin{tabular}{|c|c|c|c|c|c|c|c|}
\hline Malformation & Population & $\begin{array}{c}\text { With } \\
\text { monte-lukast }\end{array}$ & OR/RR & $95 \%$ CI & $\begin{array}{l}\text { With other long-acting } \\
\text { anti-asthmatics }\end{array}$ & OR & $95 \% \mathrm{CI}$ \\
\hline Any & 65247 & 30 & 1.07 & $0.74-1.55$ & 1151 & 1.07 & 1.01-1.14 \\
\hline Rel. severe & 46818 & 23 & 1.17 & $0.77-1.78$ & 848 & 1.11 & 1.04-1.19 \\
\hline Any cardiac defect & 10513 & 8 & 1.16 & $0.50-2.29 \#$ & 364 & 1.13 & $1.02-1.20$ \\
\hline $\begin{array}{l}\text { "Other congenital limb } \\
\text { anomaly"** }\end{array}$ & 3971 & 9 & 1.59 & $0.73-3.02 \#$ & 66 & 1.06 & $0.83-1.36$ \\
\hline
\end{tabular}


Table 5. Summary of groups of malformations which showed increased rates in the paper by Nelsen et al. [5]. Crude odds ratios (OR) calculated by the present author with chi-square or Fisher exact test, respectively. Reference group: no anti-asthmatic drugs or women treated with inhaled corticosteroids (ICS). Bold text shows statistical significance

\begin{tabular}{|c|c|c|c|c|c|c|}
\hline $\begin{array}{l}\text { Malformation } \\
\text { group }\end{array}$ & $\begin{array}{l}\text { ICD-9 } \\
\text { code }\end{array}$ & Reference & $\begin{array}{l}\text { Monte- } \\
\text { lukast }\end{array}$ & ICS & $\begin{array}{c}\text { OR vs. } \\
\text { reference } \\
(95 \% \mathrm{CI})\end{array}$ & $\begin{array}{c}\text { OR vs. } \\
\text { ICS } \\
(95 \% \mathrm{CI})\end{array}$ \\
\hline Total number of exposed infants & - & 38828 & 1187 & 2285 & - & - \\
\hline $\begin{array}{l}\text { Cardiac defects, excl. bulbus cordis } \\
\text { and septal defects }\end{array}$ & 746 & 269 & 14 & 16 & $\begin{array}{c}1.72 \\
(0.90-3.00)\end{array}$ & $\begin{array}{c}1.69 \\
(0.76-3.71)\end{array}$ \\
\hline Non-cardiac circulatory system & 747 & 570 & 31 & 44 & $\begin{array}{c}1.80 \\
(1.23-2.63)\end{array}$ & $\begin{array}{c}1.37 \\
(0.83-2.23)\end{array}$ \\
\hline Lower digestive system & 751 & 79 & 6 & 8 & $\begin{array}{c}2.48 \\
(0.79-8.33)\end{array}$ & $\begin{array}{c}0.91 \\
(0.34-2.22)\end{array}$ \\
\hline $\begin{array}{l}\text { Non-deformity limb } \\
\text { malformations }\end{array}$ & 755 & 251 & 16 & 17 & $\begin{array}{c}2.10 \\
(1.22-3.56)\end{array}$ & $\begin{array}{c}1.82 \\
(0.81-3.85)\end{array}$ \\
\hline
\end{tabular}

and Welfare. No external ethical committee evaluation was needed for this process.

Funding: No special funding was obtained for this study.

\section{Conflict of interest}

The author reports no conflict of interest.

\section{References}

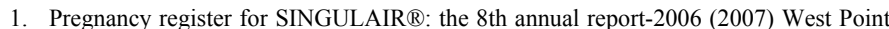
(PA): Merck Research Laboratories.

2. Kallen B, Otterblad Olausson P (2007) Use of anti-asthmatic drugs during pregnancy. Eur J Clin Pharmacol 63: 363-388. [Crossref]

3. Bakhireva LN, Jones KL, Schatz M, Klonoff-Cohen HS, Johnson D, et al. (2007) Safety of leukotriene receptor antagonists in pregnancy. J Allergy Clin Immunol 119: 618-625. [Crossref]
4. Sarkar M, Koren G, Kalra S, Ving A, Smorlesi C, et al. (2009) Montelukast use during pregnancy: a multicentre, prospective, comparative study of infant outcome. Eur J Clin Pharmacol 65: 1259-1264. [Crossref]

5. Nelsen LN, Shields KE, Cunningham ML, Stoler JM, Bamshad MJ, et al. (2012) Congenital malformations among infants born to women receiving montelukast, inhaled corticosteroids, and other asthma medications. J Allergy Clin Immunol 129: 251-254. [Crossref]

6. Kallen B, Otterblad Olausson P (2001) Monitoring of maternal drug use and infant congenital malformations. Does loratadine cause hypospadias? Int J Risk Saf Med 14 115-119.

7. National Board of Health and Welfare (2003) The Swedish Medical Birth Register: a summary of content and quality.

8. National Board of Health and Welfare (2004) Registration of congenital malformations in Swedish health registers.

9. Kallen B (2014) Risk factors for developmental dysplasia of the hip in the newborn. Data from the Swedish Medical Birth Register. Clinics Mother Child Health 11: 153.

Copyright: (C2016 Källén B. This is an open-access article distributed under the terms of the Creative Commons Attribution License, which permits unrestricted use, distribution, and reproduction in any medium, provided the original author and source are credited. 